\title{
Gêneros do discurso em cursos de Licenciaturas de Santa Catarina: o que dizem os professores
}

\author{
Rosana Mara Koerner*
}

\begin{abstract}
Resumo
A pesquisa que aqui se apresenta se inscreve nos estudos de letramento acadêmico. O objetivo da análise é identificar quais os gêneros discursivos utilizados pelos professores para e em suas práticas pedagógicas. Foram analisadas respostas a um questionário on-line e a entrevistas semiestruturadas realizadas com professores de cursos de licenciatura de universidades de Santa Catarina. Trata-se de excerto de um estudo mais amplo, sob a temática do letramento acadêmico. Com base nas proposições teóricas dos estudos sobre gêneros, especialmente na esfera acadêmica, a análise dos dados evidenciou que, além dos gêneros típicos da esfera acadêmica, há outros sendo trabalhados, muitos deles com algum propósito pedagógico. Também foi possível perceber certa relação entre a leitura e a escrita que os professores fazem para a sua prática pedagógica e aquela que solicitam aos seus estudantes. Considerando as orientações nas DCN (2019) para uma prática que implique o uso dos gêneros discursivos em todas as licenciaturas, faz-se necessário discutir com os professores formadores de professores como tais orientações se fazem presentes em suas aulas.

Palavras-chave: Professores de licenciaturas. Gêneros discursivos. Leitura e escrita. Prática docente.
\end{abstract}

\footnotetext{
* Universidade da Região de Joinville - UNIVILLE, Doutora e Mestre em Linguística Aplicada pela Universidade Estadual de Campinas (UNICAMP), Professora do Mestrado em Educação e dos Cursos de Letras e de Pedagogia. ORCID: https://orcid.org/0000-0001-6117-7537.
}

Cadernos CESPUC de Pesquisa. Série Ensaios. n.39, $2^{\circ}$ Sem./2021, p. 16-35. e-ISSN: 2358-3231 (OJS). Recebido em: 10/11/2021. Aceito em: 15/12/2021. 


\title{
Discursive Genres in Undergraduate Courses in Santa Catarina: What Teachers say
}

\author{
Rosana Mara Koerner
}

\begin{abstract}
The research presented here is part of academic literacy studies. The objective of the analysis is to identify which discursive genres are used by teachers for and in their pedagogical practices. We analyzed the answers to an online questionnaire and to semi-structured interviews conducted with professors from undergraduate courses at universities in Santa Catarina. This is an excerpt from a broader study, under the theme of academic literacy. Based on the theoretical propositions of studies on genres, especially in the academic sphere the data analysis showed that, in addition to the typical genres in the academic sphere, there are others being worked on, many of them with some pedagogical purpose. It was also possible to notice a certain relationship between reading and writing that the professors do for their pedagogical practice and the ones that they ask their students. Considering the guidelines in the DCN (2019) for a practice that implies the use of discursive genres in all degrees, it is necessary to discuss with the professors who train teachers how such guidelines are present in their lessons.
\end{abstract}

Keywords: Undergraduate teachers. Discursive genres. Reading and writing. Teaching practice.

Cadernos CESPUC de Pesquisa. Série Ensaios. n.39, $2^{\circ}$ Sem./2021, p. 16-35. e-ISSN: 2358-3231 (OJS). Recebido em: 10/11/2021. Aceito em: 15/12/2021. 


\section{Introdução}

O estudo que aqui se apresenta ${ }^{1}$ se insere no campo dos estudos de letramento, em intersecção com a área de formação docente, considerando que envolve professores de licenciaturas. A questão dos gêneros do discurso e de como se fazem presentes nas práticas de leitura e de escrita promovidas pelos professores universitários (FISCHER; DIONÍSIO, 2011; SILVA; CASTANHEIRA, 2019) está entre os enfoques assumidos pelos estudos sobre letramento acadêmico. Neste trabalho, inscrevemo-nos neste enfoque, com o objetivo de identificar os gêneros do discurso utilizados por professores de cursos de licenciaturas para e nas suas práticas pedagógicas com a leitura e com a escrita.

Temos como principal pressuposto a ideia do professor como um agente de letramento, proposta por Kleiman (2006). Os dados foram obtidos por meio de questionários on-line e entrevistas semiestruturadas com professores de universidades de Santa Catarina ${ }^{2}$, analisados com base nos conceitos basilares dos gêneros do discurso, que dão corporeidade às práticas de leitura e de escrita (BAKHTIN, 2000; SILVA; CASTANHEIRA, 2019; FISCHER; DIONÍSIO, 2011).

A temática da leitura e da escrita, no contexto universitário, desdobra-se em diferentes perspectivas de estudo: focalizando licenciandos de determinadas áreas, como Pedagogia (CARVALHO, 2002; BERTOLUCI, 2009); apresentando propostas de intervenção com vistas a ampliar as práticas de leituras e de escrita dos estudantes universitários (DUARTE, PINHEIRO e ARAUJO, 2012); buscando os aspectos implicados na possibilidade de participação de estudantes em letramentos acadêmicos (FISCHER; HOCHSPRUNG, 2017); tentando, sob o viés da Psicologia, compreender a relação entre leitura e compreensão (OLIVEIRA; DOS SANTOS, 2005); trazendo as contribuições da participação dos estudantes no Programa Institucional de Bolsas de Iniciação à Docência (Pibid) (FISCHER et al., 2016; GOMES; KOERNER, 2020); ou, ainda, relacionando a leitura com as TIC (PRÍNCIPE, 2016), para citar algumas possibilidades. A perspectiva que aqui estamos adotando é aquela que envolve os professores,

$1 \mathrm{O}$ estudo contou com a supervisão da Profa. Dra. Adriana Fischer.

2 Trata-se de um excerto de uma pesquisa sobre letramento acadêmico, que recebeu parecer favorável do Comitê de Ética e se encontra em desenvolvimento. Parte da análise dos dados já foi apresentada em evento científico em Santa Catarina.

Gêneros do discurso em cursos de Licenciaturas de Santa Catarina: 
de qualquer área, e suas práticas de leitura e de escrita, aparentemente pouco abordadas. Em geral, os estudos se têm debruçado sobre as percepções destes profissionais acerca das práticas de escrita de seus estudantes, geralmente vistas como deficitárias (CARVALHO, 2002; FIAD, 2016).

Neste sentido, parece pertinente identificar o que professores de licenciaturas leem e escrevem para a sua prática pedagógica e quais as leituras e escritas que promovem em suas aulas e, se possível, apontar uma relação entre elas. Para trabalhar com os gêneros, ele precisa reconhecer como eles funcionam e como podem ser abordados em suas práticas pedagógicas de modo a favorecer o letramento acadêmico de seu estudante. $\mathrm{Na}$ próxima seção, trazemos as contribuições de alguns autores para as reflexões sobre o papel do professor como agente de letramento.

\section{Algumas reflexões}

A escrita se mostra como objeto de estudo multifacetado, ainda mais se vista inserida no contexto universitário (BLOOME; CASTANHEIRA; LEUNG; ROWSELL, 2019), com suas várias implicações. O estudante universitário, especialmente em seu ingresso, é lançado em um fluxo intenso de leituras e de escritas, muitas inerentes à esfera (BAKHTIN, 2000) acadêmica, distintas, pois, do que até então costumava ler e escrever. Tais atividades se mostram como desafios a serem enfrentados, muito além daqueles de natureza linguística. Para Bertoluci (2009, p. 122), “[...] ]os alunos precisam ser inseridos neste novo universo e é preciso que a universidade esteja consciente e preparada para inserir seus estudantes em outras práticas e eventos de letramento, tornando possível um 'Letramento acadêmico"'.

O letramento, visto como uma perspectiva para o trabalho docente, perpassa todas as áreas, não só como um conteúdo a ser ensinado, mas, também, como eixo balizador de toda a ação pedagógica. É com tal pressuposição que compreendemos que todo o professor é um agente de letramento (KLEIMAN, 2006) e isso inclui, de forma significativa, o professor formador de formadores. Com vistas ao letramento acadêmico dos estudantes, em seu processo de inserção e manutenção, é ele quem promove 
a participação daqueles em práticas de leitura e de escrita necessárias para sua vivência no universo acadêmico.

Significativa parcela dessas práticas precisa ser ensinada já que se realiza em contextos mais complexos, geralmente relacionados ao mundo do trabalho. Eis o papel central a ser desempenhado pela universidade: o de habilitar os acadêmicos para que circulem com relativa segurança pelas diferentes práticas sociais com a escrita em seus futuros campos profissionais. Ressalta-se que a escrita está na centralidade de tudo o que se faz na universidade.

Presente no senso comum, há a ideia de que professores universitários são representantes de um elevado envolvimento com práticas de leitura e de escrita, caracterizado não só pelo volume, mas, também, pela complexidade de tais práticas. Leem livros técnicos da sua área, que exigem domínio de certa linguagem; escrevem fazendo uso desta linguagem, produzem artigos científicos ou ensaios. São, pois, insider's (GEE, 1990), legítimos exemplos de envolvimento em práticas de letramento acadêmico. Imbricam-se, pois, as experiências com a escrita/leitura já vivenciadas por este professor com aquelas que promoverá junto àqueles que serão os futuros professores.

Tardif (2011, p. 49), ao tratar dos saberes dos professores, chama de habitus as "disposições adquiridas na e pela prática real". Estamos incluindo em tais disposições, as experiências com a leitura vivenciadas pelos professores que, ainda segundo o autor, podem se transformar em "traços da personalidade profissional” (TARDIF, 2011, p. 49), manifestados em um saber-ser e em um saber-fazer. Nesta direção, podemos pensar, também, nas proposições de Hyland (2004), quando trata das práticas discursivas que caracterizam determinados grupos, aqui nos reportando ao grupo dos professores universitários.

É, pois, este sujeito, envolvido em determinadas práticas discursivas, pertencente a dado grupo social, em que se amalgamam diferentes saberes, incluindo aqueles relativos à leitura e à escrita, reconhecido como legítimo representante do contexto acadêmico, que atua como um poderoso agente de letramento, contribuindo para a formação de novos agentes, no caso das licenciaturas:

Ao mobilizar os recursos do grupo e ao promover estrategicamente a participação de todos, segundo as suas capacidades, em prol dos objetivos coletivos, o agente 
de letramento ajuda, como ator social que é, a criar contextos para que outros atores que se engajarão em atividades relevantes para o grupo venham a se constituir. (KLEIMAN, 2007, p. 422)

Esta mobilização inclui o trabalho com os gêneros do discurso (BAKHTIN, 2000), conceito que repercute nas discussões sobre letramento acadêmico (SILVA; CASTANHEIRA, 2019) e na formação de professores no Brasil. As Diretrizes Curriculares Nacionais (DCN), de 2019, em seu Art. 13 (Inciso I do Parágrafo Primeiro) preconizam a "[...] utilização dos diferentes gêneros de textos", para a formação de professores, de todas as áreas. Com base em análises de estudos divulgados em evento científico, Fischer e Dionísio $\left(2011\right.$, p. 87) ${ }^{3}$ concluíram sobre a “[...] tipificação dos textos presentes no ensino superior em dois grandes grupos: 'gêneros científicos' e as 'ferramentas pedagógicas', isto é, aqueles textos que servem de mediadores dos processos de ensino e aprendizagem, nestes se incluindo a avaliação". Para Lea ${ }^{4}$ (LILLIS; HARRIGTON; LEA; MITCHELL, 2015, p. 387), é importante verificar “[...] o modo como o gênero é articulado, frequentemente implicitamente, nos diferentes contextos institucionais" ${ }^{\text {. }}$

Todas estas reflexões ganham outros significados ao tratarmos de professores de cursos de licenciatura, referências para futuras práticas pedagógicas por parte de seus estudantes. $\mathrm{O}$ trabalho na perspectiva do letramento acadêmico implica perceber o caráter multifacetado da escrita, considerando, entre as várias facetas, o funcionamento dos gêneros típicos de tal esfera. Como Souza e Rodrigues (2020, p. 279), reconhecemos que

[...]o professor universitário tem papel fundamental na formação acadêmica dos licenciandos, visto que lhe cabe a mediação, a orientação e a promoção de diferentes práticas e eventos de letramento situados nas esferas acadêmica e docente, de modo que os estudantes se sintam pertencentes a esse ambiente[...]

Estamos aqui compreendendo que os estudos sobre letramento acadêmico se relacionam aos estudos sobre letramento do professor, incluindo-se, aqui, o professor universitário, especialmente das licenciaturas.

\footnotetext{
3 Análise de 19 estudos apresentados no evento European Conference on Reading, Braga, 18-22 de julho de 2009 (Nota 3 do artigo de Fischer e Dionísio, 2011).

4 Em diálogo com Street, na obra Working with academic literacies: case studies toward transformative practice.

5 "The way in which genre is being articulated, often implicitly, in different institutional contexts". [Tradução nossa]
} 
Assim, justificamos o nosso foco no que dizem a respeito das leituras e escritas que fazem para a sua prática pedagógica e aquelas que promovem em suas aulas, na tentativa de compreendermos as possíveis relações entre tais práticas e darmos mais visibilidade aos modos como assumem o seu papel de agentes de letramento acadêmico de seus estudantes.

\section{Metodologia}

Neste estudo, a partir de uma pesquisa envolvendo letramento acadêmico, serão discutidos dados gerados entre março e maio de 2021, por meio de um questionário on-line, respondido por 41 professores de cursos de licenciatura ${ }^{6}$ de universidades públicas e comunitárias de Santa Catarina, de diferentes áreas do conhecimento ${ }^{7}$. Foram selecionadas as universidades públicas (estadual e federal) e as comunitárias (do Sistema Acafe ${ }^{8}$ ), dada a representatividade que têm no Estado. Mediante orientação do setor de ensino de cada universidade 9 , o link do questionário foi disponibilizado aos professores, depois de encaminhado ao(à) coordenador(a) de curso ou área das licenciaturas. Dentre os 41 professores, $11^{10}$ se dispuseram a ceder uma entrevista semiestruturada, realizada em plataformas digitais. São professores de diferentes universidades: 31 possuem mestrado e 25 têm doutorado. Com relação ao tempo de serviço na IES, tem-se que: 4 trabalham entre 1 a 5 anos; 7 de 6 a 10 anos; 12 entre 11 e 20 anos; 11 entre 21 a 30 anos e 6 já estão na IES há mais de 31 anos. Do questionário serão trazidos os resultados de três questões fechadas. Os gêneros indicados para escrita foram depreendidos das entrevistas, mediante o 'olhar' atento para todas

\footnotetext{
6 Cursos nos quais atuam ou atuaram nos dois últimos anos: Pedagogia (18), Educação Física (11), Letras (11), História (7), Matemática (6), Ciências Biológicas (2), Música (2), Química (2), Ciências Sociais (2), Psicologia (1), Biologia (1), Artes Visuais (1), Dança (1), Artes (1), Educação Intercultural Indígena (1), Física (1). Um professor não respondeu. A informação foi obtida por meio de questão aberta, com o professor participante registrando o(s) curso(s).

7 Os professores são graduados em: Educação Física (5), Pedagogia (11), Letras (5), História (5), Matemática (4), Ciências Biológicas (3), Ciências Sociais (2), Filosofia (2), Educação Especial (1), Química (1), Artes Visuais (1), Geografia (1), Ciências de 1º Grau (1), sem resposta (4).

8 "A ACAFE é uma sociedade civil sem fins lucrativos que congrega as fundações educacionais criadas no Estado de Santa Catarina por lei dos poderes públicos estaduais e municipais. O objetivo desta união é promover o intercâmbio administrativo, técnico e científico entre as Instituições de Educação Superior." Disponível em https://acafe.org.br/site/. Consulta feita em 01/12/2021.

9 No total, foi encaminhado e-mail para 18 IES de Santa Catarina, entre públicas e comunitárias.

10Os professores entrevistados atuam nos seguintes cursos nos últimos dois anos: Letras (4), Dança (1), Ciências Sociais (1), História (2), Pedagogia (6), Artes Visuais (1), Ciências Biológicas (1), Educação Intercultural Indígena (1), Química (1), Física (1), Matemática (1) e Educação Física (1). São graduados em: Letras (2), Artes Visuais (1), Ciências Sociais (1), História/Geografia (1), Pedagogia (4), História (1) e Matemática (1).
}

Gêneros do discurso em cursos de Licenciaturas de Santa Catarina: 
as respostas, não só aquelas em que foram feitas as solicitações para que os professores indicassem os gêneros trabalhados, de forma explícita. Como o fio condutor das entrevistas foram os modos como atividades de leitura e de escrita são encaminhados, os gêneros acabaram sendo esparsamente mencionados. Excertos das entrevistas serão trazidos, em itálico, inseridos na discussão e, por isso, sem enumeração e uso de aspas. Os participantes serão identificados aqui como $\mathrm{P}$ (professor), seguido do número relativo ao seu questionário na planilha gerada pelo aplicativo. A identificação do curso no qual atua será feita no caso dos excertos, dado que não seria producente trazer em todos os dados apresentados.

O estudo tem uma abordagem qualitativa dos dados (LÜDKE; ANDRÉ, 1986), buscando neles recorrências e dissonâncias. Nos estudos de letramento, predominam as pesquisas de cunho etnográfico, pois possibilitam um olhar mais acurado dos usos da escrita em diferentes contextos (LILLIS; SCOTT, 2007; LILLIS, 2008; STREET, 2016), dados os procedimentos de observação direta. Questionários e entrevistas são procedimentos que servem a propósitos distintos, mas que contribuem para uma maior abrangência da pesquisa. Nesse sentido, Lillis e Scott (2007, p. 22) apontam para o desafio de desenvolver o campo de estudos e, para tal, indicam o seguinte objetivo: “• Procurar aproveitar os recursos de pesquisa que permitiriam a realização de estudos seletivamente projetados / em maior escala e / ou longitudinais ${ }^{11}$ ". No caso do presente estudo, objetivouse atingir uma maior escala, por meio da aplicação do questionário, instrumento de geração de dados que possibilita o delineamento de certo panorama, sobre o qual caberão futuras proposições de pesquisas. As entrevistas cumpriram o papel de ampliar algumas informações apenas tangenciadas no questionário.

\section{Discussões}

Iniciamos as discussões trazendo os resultados obtidos com duas questões fechadas do questionário: os participantes poderiam assinalar as alternativas que lhes eram pertinentes, e, ainda, acrescentar alguma que não estivesse sendo contemplada.

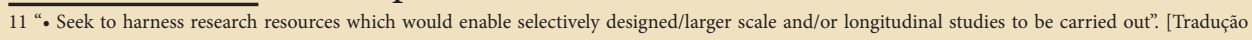
nossa] 
Com a primeira questão a ser aqui abordada tínhamos o objetivo de verificar o que o professor costuma ler para a sua prática docente nas licenciaturas. Dentre as alternativas assinaladas, houve o predomínio de artigos (97\% ${ }^{12}$ - apenas 1 professor não assinalou esta alternativa), livros especializados/técnicos (36 professores - 87\%), dissertações/teses (31 $75 \%)$ e revistas especializadas ( 27 - 65\%). Estes resultados indicam a ênfase em leituras que dão sustentação teórica às discussões que têm lugar na sala de aula; além da atualização constante na área, especialmente suprida pela leitura de artigos, teses/dissertações e revistas especializadas. Inserido em um contexto que se justifica pela produção do conhecimento que se renova constantemente, é fundamental ao professor acessar esta produção e nela pautar o seu fazer pedagógico, sob a pena de rapidamente se desatualizar. Os participantes da pesquisa parecem atentos a este aspecto, pelo menos no que se refere à leitura que fazem para a sua prática pedagógica. Contudo, reconhecemos que a simples menção à leitura de tais materiais não indica que a prática pedagógica é afetada; para tal verificação são necessárias pesquisas etnográficas, que adentrem o espaço da sala de aula, como já indicado pouco antes.

Chama a atenção a leitura da literatura, assinalada 22 vezes (53\%), especialmente considerando que foram poucos os professores de Letras (5 professores). Como a literatura adentra as aulas de disciplinas que não estão diretamente a ela ligadas? Qual a contribuição que a literatura pode trazer para o desenvolvimento das aulas? A literatura entra como um gênero na esfera acadêmica ou leitura de deleite? Talvez P13 (Ciências Sociais, graduação em Ciências Sociais) possa trazer um indicativo para possíveis respostas a estes questionamentos:

Os textos [inaudível] Darcy Ribeiro, meu Deus, aquilo é um, é tudo... [inaudível] Darcy também foi escritor de romance, né. Então, o que que essa minha vivência acabou reverberando nas minhas aulas? Eu fico surpreso, pra te falar a verdade, eu fico surpreso quando as pessoas se surpreendem com o fato de que no século $\mathrm{XXI}$ ainda exista quem leia poesia. E eu quero dizer que eu faço um uso solerte disso. Que eu falo assim, "não, eles tão equivocados, não tem problema nenhum com a poesia”...

12 Os números serão sempre trazidos sem os décimos, em respeito ao humano que há por trás deles. 
Outra explicação pode estar na compreensão de que o gosto pela literatura é parte constituinte do sujeito professor, de sua identidade, de seu habitus (TARDIF, 2011). Assim, ainda que não haja uma interferência direta, objetiva, na sua prática pedagógica, o professor pode entendê-la como constitutiva do seu fazer.

A ocorrência menor de jornais (14 vezes assinalado - 34\%) e revistas (11 vezes - 26\%) representa uma menor procura por textos que trazem notícias que poderiam se constituir em objeto de discussão no espaço da sala de aula. No contexto da pesquisa, talvez não tenham sido percebidos como algo que incida diretamente na prática docente nas licenciaturas, ainda que não seja possível separar o sujeito social do sujeito profissional. Assim como acontece com a literatura, estar atualizado nas coisas que acontecem no contexto político, econômico e social pode ser compreendido como parte da identidade do docente; contudo, diferentemente da literatura, que foi mais vezes assinalada, jornais e revistas parecem figurar como leituras à parte, não inerentes à prática pedagógica.

A leitura de Legislação (17 vezes assinalada - 41\%) indica a presença de professores que ministram disciplinas mais voltadas para o aspecto pedagógico, já que se pressupõe que sejam os documentos que direcionam a educação no país, necessários de serem conhecidos pelos estudantes, especialmente aqueles em fase de estágio nas escolas. Pode ser compreendida como um material de leitura que será objeto de estudo nas aulas, do qual o professor precisa ter domínio, até para poder promover atividades com certo posicionamento crítico.

Os demais materiais não tiveram incidência significativa, indicando que se referem a aspectos específicos discutidos por uma ou outra disciplina, como foi o caso de catálogos ( 1 ocorrência - 2\%), manuais (7 ocorrências $17 \%$ ) e jornais especializados (8 ocorrências - 19\%).

A segunda questão objetivava verificar o que professores costumam escrever para a sua prática docente nas licenciaturas. Trinta e sete professores lembraram da escrita dos planejamentos de aula, como algo que é inerente à profissão, sobre a qual deve ter domínio, até como parte do que se tem denominado letramentos do professor (KLEIMAN, 2009). São 90\% dos professores participantes que planejam as suas aulas, indicando que há preparo e que elas não acontecem no improviso, mesmo com a média de tempo de atuação superior a 15 anos para $68 \%$ dos respondentes. São, pois, 
professores experientes, muito provavelmente com domínio do conteúdo, mas que, ainda assim, preparam as suas aulas. Até porque uma aula exige toda uma sequência de procedimentos com vistas à aprendizagem dos estudantes (LIBÂNEO, 1994; SCHNEUWLY; DOLZ, 2004).

$\mathrm{Na}$ direção de uma escrita mais diretamente relacionada ao fazer pedagógico e tudo que nele está implicado, podem, ainda, ser citados o portfólio (assinalado 12 vezes - 29\%), o diário $(7$ - 17\%) e o relatório (19 - 46\%), gêneros que atendem à necessidade de registro das atividades realizadas. As nove ocorrências de manuais (22\%) talvez possam ser um indicativo da penetração de atividades relacionadas à EAD. Dos 41 professores participantes da pesquisa, 8 (19\%) atuam em cursos de licenciatura na modalidade EAD.

Também são professores envolvidos com a escrita acadêmica: artigos científicos foram assinalados 35 vezes (85\%) e capítulos para livros especializados, 21 vezes (51\%). Vale ressaltar que a questão solicitava a indicação de escritas voltadas para as aulas. Assim, cabe questionar como a escrita de artigos e capítulos pode contribuir para as aulas? São materiais posteriormente direcionados para os estudantes? De qualquer forma, a experiência de produzir este tipo de material pode contribuir para a condução das atividades de escrita de seus estudantes. Afinal, o próprio professor é um insider (GEE, 1990) neste tipo de escrita, ainda que reconheçamos que isto, por si só, não é garantia para a condução da escrita acadêmica de seus estudantes.

Até aqui trouxemos os gêneros que os professores costumam ler e escrever para a sua prática docente nas licenciaturas. A seguir, indicaremos os gêneros exigidos para a leitura e escrita dos estudantes em suas aulas. Com este movimento, tentaremos buscar alguma relação entre os grupos de gêneros: aqueles que o professor usa para ler/escrever e aqueles que pede que seu aluno leia/escreva.

Iniciaremos com a leitura, cujos resultados foram gerados por meio de uma questão fechada, na qual os professores poderiam assinalar quantas alternativas julgassem pertinentes. A alternativa capítulos e/ou livros foi assinalada 40 vezes (97\%) e artigos acadêmicos, 39 vezes (95\%), constituindo-se nos dois materiais de leitura de uso majoritário no espaço acadêmico. Tais resultados coincidem com a resposta sobre as leituras dos professores, apenas na ordem invertida. Parece possível supor que as leituras 
realizadas pelo professor são aquelas que ele direcionará para a leitura de seu estudante, nas aulas. Compreendemos isto como mais um indicativo de que há preparo para o que acontecerá nas aulas desses profissionais, incluindo-se as práticas de leituras que nelas acontecerão:

Então, eu tenho a impressão que quando nós indicamos as leituras, já, né, “olha, leiam o artigo tal", "ó, estou fazendo a leitura da dissertação tal, tá bem interessante, depois que a dissertação for publicada, eu aconselho vocês a procurar", esse tipo de diálogo, né, eu vou travando com os alunos, de certa forma já indica, né, uma orientação pra que eles também busquem, né. (P42 - Pedagogia, graduação em Letras)

Documentos/legislação, assinalada por 20 professores (48\%) e TCE, TCC, Monografias (15 ocorrências - 36\%) aparecem em seguida. Como indicado pouco antes, muitos professores atuam em turmas concluintes, já em fase de realização do estágio, o que explica a relativa incidência na leitura desses materiais. Além disso, também muitas das disciplinas ministradas pelos participantes são do Grupo I das DCN/2019, relativo ao conhecimento da área (pedagógico), o que explica a significativa referência aos documentos, provavelmente ligados à área da educação. A legislação também foi citada por quase $50 \%$ dos professores como leitura para a prática docente, o que reforça a ideia de preparo para as aulas. TCE, TCC e Monografias não constavam como alternativa na pergunta sobre as leituras do professor. Contudo, são materiais que, inevitavelmente, são por ele lidos na condição de avaliadores do 'produto' final do período de estágio.

Novamente chama a atenção a leitura ficcional, indicada 6 vezes (14\%). Cinco desses professores são formados em Letras e apenas $1 \mathrm{em}$ Pedagogia. Embora um tanto distintos daqueles resultados relativos aos professores, quando 22 deles indicaram que costumam ler literatura para a sua prática docente, tais resultados reforçam a ideia de que as experiências de leitura dos professores de alguma forma se refletem naquilo que eles propõem como leitura para os seus estudantes (dos 6 professores, apenas 2 ministram aulas explicitamente relacionadas à literatura). Cabe aqui retomar os questionamentos já feitos acima, quando discutíamos a leitura dos professores para ressignificá-los na perspectiva da leitura exigida para o estudante: como a leitura da literatura pode contribuir para as discussões 
que têm lugar em disciplinas que não estão diretamente a ela ligadas? Qual a função que cumprem? Novamente recorremos a P42 (Pedagogia, graduação em Letras) para sugerir alguns indicativos de resposta a tais questionamentos:

[...] toda abertura de aula eu peço pra algum aluno trazer um livro de literatura pra ler, às vezes eles até me perguntam, "ah, pode ser um poema pra adulto, não tem problema?", "não, não tem problema, podem trazer". Então acaba variando um pouco, geralmente é a literatura de ficção pra criança, né, e poemas, e aí os poemas também variam, às vezes trazem literatura...

Então eu gosto, assim, de mesclar um pouco essa ideia de que não é só isso aqui, né, não é só a questão acadêmica, mas tem a questão pra mim que é estética, né, da arte. Falo muito de museus que eu gosto de visitar, conto alguns projetos desenvolvidos em torno da literatura, em torno de obras de arte, também, que a gente vem acompanhando em alguns, né, em alguns momentos... Então é um pouco isso, assim, que eu faço com a intenção realmente de provocar essa ampliação de repertório, né, a gente fala muito nessa ideia de ampliação de repertório.

Enquanto tivemos nove professores que leem manuais, quatro solicitam a leitura deste material para os estudantes (só dois dentre os nove). Três professores trouxeram outras possibilidades de leitura não atendidas na questão: um professor assinalou reportagens, outro 'conteúdos independentes' e um terceiro partes de teses e dissertações.

No caso dos gêneros indicados para atividades de escrita dos estudantes não houve uma questão específica, já que tínhamos a intenção de verificar como o professor ia conduzindo tais atividades e, para tal, pareceu-nos que a referência ao gênero trabalhado seria feita quase que naturalmente. Assim, para o caso da escrita, iremos apresentar os gêneros que pudemos depreender dos dados das entrevistas com os professores, sem a preocupação quanto à quantidade de vezes que foram citados. Houve a ocorrência dos seguintes gêneros discursivos ${ }^{13}$ : artigos, resumos, entrevistas, literatura infantil, conto, vídeos, áudios, apresentação em ppt [Power Point],

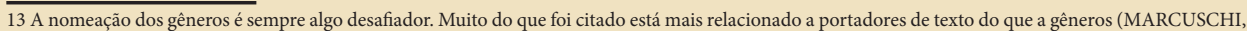
2000); contudo, optamos por registrar para levar em consideração o movimento que o professor faz envolvendo a leitura e a escrita. Há alguns que estão estreitamente relacionados a estratégias de ensino, como é o caso da nuvem de palavras e das cruzadas.
}

Gêneros do discurso em cursos de Licenciaturas de Santa Catarina: 
Trabalhos de Conclusão de Curso, carta, carta enigmática, fichamento, texto monográfico, avaliações, fórum, exercícios, mapa mental, síntese, diário (de campo), relatórios, roteiro de entrevista, tabelas, levantamento bibliográfico, memorial, autoavaliação, planos de aula, RPG [Role Playing Game], projetos, ensaios, resenha, nuvem de palavras, palavras cruzadas, portfólio, chat, desenho em quadrinhos e legenda.

Indicaremos, a seguir, algumas percepções com base nestes dados. Uma delas se refere à variabilidade dos gêneros mencionados pelos professores. Isto parece apontar para certa diversificação das propostas, o que pode contribuir, talvez, para uma prática pedagógica pautada no diverso e não no reiterado uso de certos gêneros.

Outra percepção diz respeito à função que os gêneros assumem nas aulas. De uma forma ou de outra, todos os gêneros trabalhados em espaços/ tempos de ensino acabam assumindo alguma função pedagógica, como indicado por Schneuwly e Dolz (2004, p.75), quando propõem a noção de gênero como "[...] mega-instrumento que fornece um suporte para a atividade nas situações de comunicação e uma referência para os aprendizes". Alguns dos gêneros citados funcionam como ferramentas pedagógicas que, "[...] servem de mediadores dos processos de ensino e aprendizagem, nestes se incluindo a avaliação[...]" (FISCHER; DIONÍSIO, 2011, p. 87), muito presentes nas atividades de escrita, lembrando que muito do que se propõe como avaliação na universidade é feito por escrito. Podem ser citados: cartas, cartas enigmáticas, fichamentos, fórum, mapa mental, sínteses, palavras cruzadas, RPG [Role Playing Game], prova escrita, ppt [Power Point], entre outros. Interessante destacar que nenhum destes gêneros foi citado como sendo escrito pelo professor para a sua prática docente. Como ferramentas pedagógicas, talvez tenham sido indicadas no planejamento de aula, cuja escrita 37 professores assinalaram que costumam escrever.

No caso dos gêneros científicos, que contribuem para o desenvolvimento científico do estudante (FISCHER; DIONÍSIO, 2011), não houve uma variabilidade tão significativa, se considerarmos aqueles típicos (MARCUSCHI, 2000) da esfera acadêmica: resumos, relatórios, artigos, projetos, ensaios, resenhas. O segundo gênero mais citado pelos professores foi o gênero artigo como escrita costumeira para a sua prática docente. Não é uma escrita simples e que exige ter algo de científico a ser dito. 
Alguns desses gêneros ficam no entrelugar do científico e do pedagógico, como é o caso do memorial e do portfólio, que possibilitam ao estudante fazer reflexões sobre suas escolhas e seus fazeres no ambiente acadêmico $^{14}$. Aqui é possível relacionar com a escrita feita pelo próprio professor, já que 12 deles indicaram escrever portfólios.

Também foi possível perceber certa 'flutuação’ na identificação (ou não) dos gêneros feita pelos professores. Certas expressões não deixam evidentes quais os gêneros abordados nas aulas: materiais, conceitos, palavras-chave, tópicos, dissertar, página. A palavra texto parece cumprir o papel de um termo 'genérico', usado por todos os professores nas entrevistas. Excetuando-se alguns professores (principalmente os da área de Letras), durante as entrevistas, foi necessário, em alguns momentos, esclarecer o que estava sendo entendido com o termo 'gênero', presente em algumas questões (e nas DCN mais recentes!), alternando com a expressão 'tipo de texto'15. A nomeação explícita do gênero proposto para leitura e para escrita contribui para o resgate dos aspectos que lhe são inerentes, conforme Bakhtin (2000) propõe, sintetizado como estrutura composicional, conteúdo e estilo. O professor, ao propor a escrita de um resumo, por exemplo, remete o estudante a estes aspectos (desde que já tenha havido um trabalho anterior com o gênero). Isto não acontece quando a proposta é a escrita de um texto: qual texto? com qual propósito? com qual configuração?

Finalmente, o momento ${ }^{16}$ em que o ensino se encontrava quando os dados foram gerados, com as aulas acontecendo em formato on-line, pode ter influenciado na indicação de alguns gêneros típicos do ambiente digital: nuvem de palavras, chat, fórum. Talvez ocorressem em momentos anteriores, mas, desde que feitos arranjos de equipamentos; no momento da geração dos dados, tudo já estava arranjado para as aulas no formato online. Talvez o uso episódico destes gêneros, antes da pandemia, possa vir a se tornar corriqueiro em momentos posteriores.

São gêneros que nos remetem à ideia dos gêneros (trans)midiáticos (ARANDA; FREIRE, 2020), aos quais se somam outros, mais comuns

\footnotetext{
14 Vale ressaltar que memoriais estão servindo, por exemplo, para o ingresso de candidatos a programas de pós-graduação.

15 Estamos conscientes de que 'tipos de textos' não se refere a gêneros, contudo, trata-se de expressão mais usual para os professores o que poderia contribuir para a sua compreensão quanto ao que esperávamos dele em uma determinada questão.

16 Em 2021, início do ano, as aulas presenciais ainda estavam suspensas em função das restrições impostas pela pandemia causada pela Covid 19.
}

Gêneros do discurso em cursos de Licenciaturas de Santa Catarina: 
em práticas pedagógicas, não só com a escrita: documentários, vídeos informativos, filmes, áudios. Há múltiplas semioses envolvidas, apontando o envolvimento do estudante em atividades de leitura e de escrita para além do limite do texto escrito.

\section{Algumas Considerações}

Nossa intenção neste estudo foi identificar o que professores de licenciaturas leem e escrevem para a sua prática pedagógica e quais as leituras e escritas que promovem em suas aulas e, se possível, apontar uma relação entre elas. Como fio condutor, mantivemos a ideia do professor como agente de letramento, no caso do contexto universitário, aquele que promove o letramento acadêmico de seus estudantes por meio de propostas de práticas de leitura e de escrita.

Inserido em um contexto que se justifica pela produção do conhecimento que se renova constantemente, é fundamental ao professor acessar esta produção e nela pautar o seu fazer pedagógico, sob a pena de rapidamente se desatualizar. Os participantes da pesquisa parecem atentos a este aspecto, pelo menos no que se refere à leitura que fazem para a sua prática pedagógica, marcada pela significativa recorrência a artigos científicos e a livros especializados. Contudo, reconhecemos que a simples menção à leitura de tais materiais não indica que a prática pedagógica seja afetada; para tal verificação são necessárias pesquisas etnográficas, que adentrem o espaço da sala de aula (LILLIS; SCOTT, 2007; LILLIS, 2008; STREET, 2016).

No caso das escritas nas quais os professores se envolvem, sobressaiu o planejamento das aulas, inerente a sua profissão. Vale ressaltar que, mais uma vez, artigos científicos e capítulos de livros especializados foram significativamente referenciados, sublinhando o caráter acadêmico que parece predominar nas práticas de leitura e de escrita dos participantes da pesquisa.

Resultados muito semelhantes foram gerados no que se refere às leituras solicitadas aos estudantes, predominando, mais uma vez, os artigos acadêmicos e os capítulos e/ou livros. O caráter acadêmico está, pois, na 
centralidade da ação dos professores, tanto nas suas próprias leituras e escritas, que fazem para as suas práticas docentes, como nas leituras que solicitam aos seus estudantes, arriscando-nos a sintetizar tal conclusão com a expressão 'paralelismo'. Até no que se refere à leitura de literatura e de documentos oficiais (legislação) este 'paralelismo' ocorre, embora em proporções menores.

No caso das práticas de escrita solicitadas aos estudantes, destacouse a significativa variabilidade, indicando um interessante movimento de diversificação por parte dos professores. Os gêneros típicos da esfera acadêmica, como resenhas, projetos, ensaios e artigos, foram mencionados, mas, também, outros que funcionam como ferramentas pedagógicas: roteiros de entrevistas, TCC, cartas, por exemplo. Um aspecto que chamou a atenção foi a fluidez na identificação dos gêneros, muitas vezes referidos tão somente pela palavra 'texto', nomeação que pouco evidencia o que se pretende que os estudantes produzam. Sobre a incidência de gêneros do ambiente digital, creditada, em parte, à mudança das aulas do presencial para o on-line, resta a dúvida sobre sua permanência quando do restabelecimento das aulas nos seus formatos originais.

De qualquer forma, os resultados indicaram que os professores universitários participantes da pesquisa, assumem uma perspectiva acadêmica nas leituras e escritas que fazem para a sua prática pedagógica e, também, naquelas que promovem em suas aulas, junto aos seus estudantes. Ainda que a nossa opção metodológica não nos permita afirmar que as práticas de leitura e de escrita propostas promovam o letramento acadêmico do estudante, inserindo-o plenamente no contexto universitário, os dados gerados fornecem um cenário bastante favorável para tal. Reconhecemos que a simples proposição de dadas leituras e escritas não é garantia para o letramento acadêmico; há muitos aspectos a serem observados. Contudo, não podemos desprezar que os resultados deste estudo permitem entrever gestos dos professores atuando como agentes de letramento.

Daí a nossa indicação para pesquisas que adentrem o espaço universitário e suas salas de aula, considerando o professor e suas práticas e o quanto elas contribuem para o letramento acadêmico dos estudantes. A utilização dos diferentes gêneros de discursos na formação docente, como uma orientação das DCN (2019), precisa ser discutida com os professores formadores de professores de todas as áreas para que repercuta em suas 
práticas pedagógicas. Nesse sentido, entendemos que ainda se faz necessário melhor compreender os modos como o professor universitário exerce o seu papel de agente de letramento e, nessa direção, otimizar os esforços para que tal papel seja plenamente exercido.

\section{Referências}

ARANDA, M. del C. de la T.; FREIRE, M. M. Narrativas transmídia: entre multiletramentos e letramentos transmídia, o que levar para a aula de línguas? Trabalhos em Linguística Aplicada, Campinas, n.59.2: 15311554, mai./ago. 2020.

BAKHTIN, M.. Estética da criação verbal. Tradução de Maria Ermantina Galvão G. Pereira. São Paulo: Martins Fontes, 2000.

BERTOLUCI, K. N. Letramento acadêmico: leitura(s) em um curso de Pedagogia. Ao Pé da Letra. Vol. 11.2, p. 105 - 124, 2009.

BLOOME, D., CASTANHEIRA, M. L., LEUNG, C. \& ROWSELL, J. Retheorizing Literacy Practices: Complex social and cultural contexts. New York: Taylor \& Francis, 2019.

BRASIL. Ministério da Educação. CNE/CEB. Diretrizes Curriculares Nacionais para a Formação de Professores. Brasília, 2019.

CARVALHO, M. A leitura dos futuros professores: por uma pedagogia da leitura no ensino superior. Teias: Rio de Janeiro, ano 3, n 5, p. $01-10$, jan/ jul 2002.

DUARTE, A. L. M., PINHEIRO, R. C. \& ARAUJO, J. A leitura acadêmica na formação docente: dificuldades e possibilidades. Revista De Letras, $\mathrm{N}^{\mathrm{O}}$. 31, Vol. (1/2), p. 102 - 108, jan./dez. - 2012.

FIAD, R. S. (org.). Letramentos acadêmicos: contextos, práticas, percepções. São Carlos: Pedro \& João Editores, 2016.

FISCHER, A. \& HOCHSPRUNG, V. Prática de escrita na universidade: A perspectiva dos letramentos acadêmicos sobre produções de estudantes de 
letras. Miguilim - Revista Eletrônica do Netll, V. 6, No. 3, p. 44-66, set.dez. 2017.

FISCHER, A. \& DIONÍSIO, M. de L. Perspectivas sobre letramento(s) no ensino superior: objetos de estudo em pesquisas acadêmicas. Atos de Pesquisa em Educação, Blumenau-SC, v. 6, n. 1, p. 79-93, jan./abr. 2011. DOI: http://dx.doi.org/10.7867/1809-0354.2011v6n1p79-93. Acesso em: 19 junho 2021.

FISCHER, A., GUSE, A. F. \& VICENTINI, M. A. Letramentos acadêmicos em foco: movimentos dialógicos em práticas do PIBID. In: FIAD, R. S. (org.). Letramentos acadêmicos: contextos, práticas, percepções. São Carlos: Pedro \& João Editores, 2016. p. 99-128.

GEE, J. P. Social Linguistics and Literacies: ideologies in Discourse. London: Falmer Press, 1990.

HYLAND, K. Disciplinary discources: social interactions in academic writing. Michigan: University of Michigan, 2004.

KLEIMAN, A. B. Professores e agentes de letramento: Identidade e posicionamento social. Filologia e Língua Portuguesa, n. 8, p. 409-424, 2006.

KLEIMAN, Â. B. Letramento e Formação do Professor: Quais as práticas e exigências no local de trabalho? In: KLEIMAN, Â. B. (org.). A formação do professor: perspectivas da linguística aplicada. Campinas: Mercado de Letras, 2009.

LEA, M. Revisiting the question of transformation in academic literacies: the ethnographic imperative: Brian Street in conversation with Mary Lea and Theresa Lillis. In: LILLIS, t., HARRIGTON, K., LEA, M. \& MITCHELL, S. (org.). Working with academic literacies: case studies toward transformative practice. Fort Collins - Colorado: WAC Clearinghouse, 2015. p. 383-390.

LIBÂNEO, J. C. Didática. São Paulo: Cortez, 1994. 
LILLIS, T. \& SCOTT, M. Defining academic literacies research: issues of epistemology, ideology and strategy. Journal of Applied Linguistics, vol. 4.1, p. 5-32, 2007, DOI: 10.1558/japl.v4i1.5. Acesso em: 10 junho 2021.

LILLIS, T. Ethnography as Method, Methodology, and "Deep Theorizing": Closing the Gap Between Text and Context in Academic Writing Research. Written Communication. Volume 25, Number 3, 353-388, July, 2008.

LÜDKE, M.; ANDRÉ, M. E. D. A. Pesquisa em educação: abordagens qualitativas. São Paulo: EPU, 1986.

MARCUSCHI, L. A. Gêneros textuais: o que são e como se constituem. Universidade Federal de Pernambuco. Recife, janeiro de 2000 (mimeo.)

OLIVEIRA, K. L. de. \& DOS SANTOS, A. A. A. Compreensão em leitura e avaliação da aprendizagem em universitários. Psicologia: Reflexão e Crítica, 18(1), pp. 118-124, 2005.

PRÍNCIPE, G. S. Práticas letradas mediadas pela tecnologia digital no ensino técnico integrado ao médio: discussão acerca da escrita de uma monografia como Trabalho de Conclusão de Curso. In FIAD, R. S. (org.). Letramentos acadêmicos: contextos, práticas, percepções. São Carlos: Pedro \& João Editores, 2016. p. 99-128.

SCHNEUWLY, B.; DOLZ, J. e Colaboradores. Gêneros orais e escritos na escola. Tradução de R. Rojo e Glais S. Cordeiro. Campinas-SP: Mercado de Letras, 2004.

SILVA, E. M. da; CASTANHEIRA, M. L. Práticas de letramento acadêmico: uma análise das condições de produção da escrita em cursos de geografia. Diálogo das Letras, Pau dos Ferros, v. 8, n. 3, p. 2-21, set./dez. 2019.

STREET, B. Learning to read from a social practice view: Ethnography, schooling and adult learning. Prospects, 46:335-344, 2016. https://doi. org/10.1007/s11125-017-9411-Z

TARDIF, M. Saberes docentes e formação profissional. 12 ed. PetrópolisRJ: Vozes, 2011. 